\title{
Proceeding
}

6th INSHS International Christmas Sport Scientific Conference, 11-14 December 2011. International Network of Sport and Health Science. Szombathely, Hungary

\section{Diet-Induced thermogenesis: comparison of two isocaloric meal-replacement shakes. A pilot study}

\author{
MICHAL KUMSTÁT ${ }^{1}$, LUBOŠ HRAZDIRA² \\ ${ }^{1}$ Department of health promotion, Faculty of sport studies, Masaryk University, Brno, Czech Republic \\ ${ }^{2}$ The Czech Society of Sport Medicine, Jílkova, Czech Republic
}

\begin{abstract}
Kumstát M, Hrazdira L. Diet-Induced Thermogenesis: Comparison of Two Isocaloric Meal-Replacement Shakes. A pilot study. J. Hum. Sport Exerc. Vol. 7, No. Proc1, pp. S140-S146, 2012. The aim of this study is to evaluate the differences in diet-induced thermogenesis (DIT) between two liquid meal-replacement shakes of different macronutrient compositions: high protein (HP) and high carbohydrate $(\mathrm{HC})$ meal. Five male subjects $\left(26 \pm 3.7 \mathrm{y}\right.$, body mass index $\left.24.6 \pm 1.7 \mathrm{~kg} \cdot \mathrm{m}^{-2}\right)$ completed the crossover, single-blind study. During two separate occasions (non-consecutive days) indirect calorimetry measurement was taken. Production of $\mathrm{CO}_{2}$, consumption of $\mathrm{O}_{2}$ and respiratory exchange ratio were monitored before and after ingestion of two isocaloric liquid meals with energy content of $7 \mathrm{kcal} / \mathrm{kg}$ per fat free weight. The postprandial period measurement lasted 180 min. Nonparametric statistics was used and value of 0.05 was accepted as the limit of significance. An immediate and persistent thermic effect was caused by the test meals. The total DIT calculated in HP and HC meals was: $51.8 \pm 17.2 \mathrm{kcal} / 180 \mathrm{~min}$ and $32.13 \pm 13.4 \mathrm{kcal} / 180 \mathrm{~min}$, respectively (where $p=0.14$ ). No statistically significant difference in postprandial energy expenditure between HP $\left(0.29 \pm 0.10 \mathrm{kcal} \cdot \mathrm{min}^{-1}\right)$ and $\mathrm{HC}\left(0.18 \pm 0.07 \mathrm{kcal} \cdot \mathrm{min}^{-1}\right)$ meals was observed (where $p=$ 0.14). Elevated values of energy expenditure did not return to the baseline after 3 hours. The DIT, expressed as percentage of energy consumed, averaged $8.7 \pm 2.9 \%$ for the HP meal, compared to $5.4 \pm$ $2.3 \%$ for the $\mathrm{HC}$ meal (where $\mathrm{p}=0.14$ ). Results indicate that the macronutrient composition plays a significant role in metabolic responses. It was concluded that an increment in the energy expenditure above the baseline after ingestion of either protein-like or maltodextrin-like test meals is comparable. Key words: THERMIC EFFECT OF FOOD, INDIRECT CALORIMETRY, PROTEINS, CARBOHYDRATES.
\end{abstract}

\footnotetext{
Corresponding author. Faculty of sport studies, Department of health promotion, Kamenice 5, 62500, Brno.

E-mail: kumstat@fsps.muni.cz

6th INSHS International Christmas Sport Scientific Conference, 11-14 December 2011. International Network of Sport and Health Science. Szombathely, Hungary

JOURNAL OF HUMAN SPORT \& EXERCISE ISSN 1988-5202

(c) Faculty of Education. University of Alicante

doi:10.4100/jhse.2012.7.Proc1.15
}

VOLUME 7 | Proc1 | 2012 | S140 


\section{INTRODUCTION}

There are three basic components of human energy expenditure: basal energy expenditure, thermic effect of food and energy cost of physical activity. Thermic effect of food or diet induced thermogenesis (DIT) is the increase in energy expenditure above resting levels associated with the digestion, intestinal absorption, initial steps of metabolism and storage of nutrients. A mix diet consumed at energy balance results in approximately $5-15 \%$ of total daily energy expenditure (Westerterp, 2004). The magnitude of DIT is proportional to the energy content and the macronutrient composition of the meal. Dietary protein stimulates thermogenesis more than carbohydrate or fat (Stipanuk, 2006). Acheson et al. (2011) suggest that different dietary sources of protein might differ in their effect on energy metabolism in young lean males. Similarly Blaak and Saris (1996) found considerably different postprandial thermogenesis after ingestion of different types of carbohydrate.

Nowadays, sport drinks and meal replacement food is a standard form of supplementing athlete's nutrition, with an additional role in the weight-loss industry (Scott and Devore, 2004). Different sources of proteins or carbohydrates are used. Prat-Larquemin et al. (2000) showed variations in sucrose vs. maltodextrin outcome on DIT in healthy young males.

The possible relation between postprandial effect of protein and maltodextrin and mutual combination has not been studied yet. The degree to which interindividual characteristics, such as physical fitness or body composition contribute to variation in DIT remains unclear. The present pilot study aimes to evaluate the differences in diet-induced thermogenesis between two liquid meal-replacement shakes of different macronutrient composition.

According to the accepted knowledge, we hypothesise, that the thermic effect of the HP meal would be higher in comparison with the $\mathrm{HC}$ meal.

\section{MATERIAL AND METHODS}

\section{Subjects}

Five male subjects $(26 \pm 3.7 \mathrm{y}, 182.5 \pm 4.5 \mathrm{~cm}, 82.1 \pm 8.9 \mathrm{~kg})$ - volunteers from the university community participated in the study. All subjects were healthy, non-smokers and were not taking medications of any kind. All participants were engaging in regular activity in the previous 1 year (at least 6 hours/week). They were weight stable for at least 6 month prior to the study. The written informed consent of all subjects was obtained and the protocol was approved by the Department of health promotion at Faculty of sport studies. Table 1 gives detailed subjects characteristics. Participants completed crossover, single-blind study.

\section{Procedures}

Laboratory procedures were performed at the Faculty of sport studies. Subjects reported to the laboratory on two separate occasions with an interval of at least 1 week. All subjects were asked to come to the laboratory by car or by bus. Moreover, subjects were asked to refrain from using alcohol and to keep 3 days dietary record to complete the subjects' nutritional status prior to the testing. The subjects refrained from strenuous activity on the day before each trial. The testing was performed at 7:00 a.m. in the postabsorptive state after 12-h fast on two non-consecutive days (to avoid possible carryover effects between treatments). Resting energy expenditure (post-absorptive) was measured by indirect calorimetry using complex cardiopulmonary metabolic system Cortex MetaLyzer 3B. After 15 min of rest period the baseline measurement was recorded for $15 \mathrm{~min}$, or until steady state was reached. The subjects then consumed 
isocaloric liquid meal corrected for the individual level of fat free weight ( $7 \mathrm{kcal} /$ fat free weight). The test meal was consumed within $10 \mathrm{~min}$. Two meal replacement shakes were used on the two separate occasions. The high protein (HP) and high carbohydrate $(\mathrm{HC})$ meal provides in total $512 \pm 62.5 \mathrm{kcal}$. Table 2 gives their detailed characteristics. During following postprandial period (3-h), last 10 min of every half-hour was recorded and assessed.

Table 1. Physical characteristics of subjects $(\bar{x} \pm S D)$

\begin{tabular}{|l|c|}
\hline Variable & Subjects $(\mathbf{n}=\mathbf{4})$ \\
\hline Age $(\mathbf{y})$ & $26.3 \pm 3.7$ \\
\hline Weight & $82 \pm 8.9$ \\
\hline Height $(\mathbf{c m})$ & $182.5 \pm 4.5$ \\
\hline Body mass index $\left(\mathbf{k g} / \mathbf{m}^{2}\right)$ & $24.6 \pm 1.7$ \\
\hline Body fat $(\%)$ & $9.4 \pm 0.9$ \\
\hline Fat free mass (kg) & $73.2 \pm 8.9$ \\
\hline RMR (kJ/day) & $9519.6 \pm 781.4$ \\
\hline
\end{tabular}

NOTE: $R M R$ = resting metabolic rate. Presented value is the mean of two separate measurements.

During the measurements subjects were awake and lay quietly and motionless. The gas analyzer was recalibrated before each laboratory procedure. The laboratory was maintained at $24^{\circ} \mathrm{C}$ throughout the study. Laboratory conditions did not allow to accurately assess total urinary nitrogen excretion. Oxygen uptake and dioxide production were analysed. Energy expenditure and respiratory exchange ratio were calculated and the result was converted to kilocalories using the Weir formula (Weir, 1949). Protein utilization under resting conditions was assumed to be negligible. Steady state conditions (allowable deviations) were set as follows: $\mathrm{V}^{\prime} \mathrm{CO}_{2}(10 \%), \mathrm{V}^{\prime} \mathrm{O}_{2}(10 \%)$, RER (5 \%) (Reeves et al., 2004). Cardiopulmonary metabolic system used breath-by-breath monitoring (the average of 9-13 breaths was calculated) and participants were given mouthpieces of proper size (volume 47 or $49 \mathrm{ml}$ ). Body composition was obtained by bioelectric impedance analysis (InBody 230).

Laboratory protocol corresponds to the similarly designed diet-induced thermogenesis researches found in the scientific literature.

\section{Statistics}

All values are presented as the SD. To indicate significant changes in the response pattern after ingesting the test meals, a nonparametric Wilcoxon matched pair test was used. For statistical comparisons between the test meals, metabolic responses were calculated as means of two separate tests. P value of 0.05 was accepted as the limit of significance. Coefficient of variation of RMR was measured as: where $s$ is the sample standard deviation and is the sample mean. 


\begin{tabular}{|c|c|c|c|c|c|}
\hline \multicolumn{7}{|c|}{ Table 2. The test meal characteristics (per 100 g / powder). } \\
\hline $\begin{array}{c}\text { Test } \\
\text { meal }\end{array}$ & $\begin{array}{c}\text { Energy content } \\
\text { (kj / kcal) }\end{array}$ & Protein (g) & Carbohydrate $(\mathbf{g})$ & $\begin{array}{c}\text { Fat } \\
\text { (g) }\end{array}$ & $\begin{array}{c}\text { Dietary } \\
\text { fiber }\end{array}$ \\
\hline HP & $362 / 1534$ & $\begin{array}{c}85 \text { (milk protein, whey protein- } \\
\text { lactalbumines / lactoglobulines, } \\
\text { powdered egg white) }\end{array}$ & $\begin{array}{c}1.5 \text { (aspartam, } \\
\text { asesulfam-K) }\end{array}$ & 1.5 & $\begin{array}{c}1 \text { (guar } \\
\text { gum) }\end{array}$ \\
\hline HC & $400 / 1680$ & 0 & 100 (maltodextrin) & 0 & \\
\hline \multicolumn{7}{|c|}{ NOTE: $H P=$ high protein; $H C=$ high carbohydrate } \\
\hline
\end{tabular}

\section{RESULTS}

The testing meals caused an immediate and persistent thermic effect. The total DIT calculated was not significantly higher in HP and HC meals $(51.8 \pm 17.2 \mathrm{kcal} / 180 \mathrm{~min}$ and $32.13 \pm 13.4 \mathrm{kcal} / 180 \mathrm{~min}$, respectively, where $p=0.14$ ) (Table 3 ). Interestingly, no statistically significant difference in the postprandial energy expenditure between HP $(0.29 \pm 0.10 \mathrm{kcal} \cdot \mathrm{min}-1)$ and $\mathrm{HC}\left(0.18 \pm 0.07 \mathrm{kcal} \cdot \mathrm{min}^{-1}\right)$ meals was observed $(p=0.14)$ (Table 3). Elevated values of energy expenditure did not returne to the baseline after 3 hours. Peak oxygen consumption was reached at $90 \mathrm{~min}$ in both test meals (Figure 1). The DIT expressed as the percentage of energy consumed averaged $8.7 \pm 2.9 \%$ for the HP meal, compared to $5.4 \pm 2.3 \%$ for the $\mathrm{HC}$ meal $(p=0.14)$.

Table 3. Resting metabolic rate and thermic effect of testing meals.

\begin{tabular}{|c|c|c|c|}
\hline Variable & $\begin{array}{l}\text { High protein } \\
\text { meal }\end{array}$ & $\begin{array}{c}\text { High carbohydrate } \\
\text { meal }\end{array}$ & $p$ \\
\hline RMR (kcal/min) & $1.55 \pm 0.15$ & $1.59 \pm 0.11$ & 0.46 \\
\hline$\Delta$ DIT (kcal/min) & $0.29 \pm 0.10$ & $0.18 \pm 0.07$ & 0.14 \\
\hline 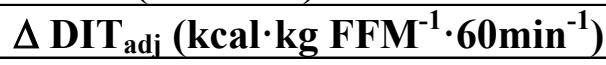 & $0.24 \pm 0.08$ & $0.15 \pm 0.05$ & 0.14 \\
\hline DIT total (kcal/180 min) & $51.8 \pm 17.21$ & $32.13 \pm 13.38$ & 0.14 \\
\hline DIT (\%) & $8.74 \pm 2.90$ & $5.42 \pm 2.26$ & 0.14 \\
\hline
\end{tabular}

NOTE: Values are expressed as $\bar{x} \pm S D ; R M R=$ resting metabolic rate; $D I T=$ diet induced thermogenesis; $\triangle D I T=(\bar{x} 30-180 \mathrm{~min})-$ RMR; DIT total $=([\bar{x} 30-180 \mathrm{~min}]-R M R)] \times 180 \mathrm{~min} ; \mathrm{DIT}(\%)=$ DIT total/energy ingested (adapted from Poehlman et al., 1988).

\section{DISCUSSION}

The study was designed to determine the thermic response to high protein or high carbohydrate meal replacement shake. In a similar study Scott and Devore (2005) showed that HP meal invoke significantly different response over 3-h period than $\mathrm{HC}$ meal. 
Generally, the reported DIT values for separate nutrients are $0-3 \%$ for fat, $5-10 \%$ for carbohydrate and 20 - $30 \%$ for protein (Westerterp, 2004). Our results however failed to confirm the dominant role of protein. Although we found stronger impact of the protein fraction on DIT, the result was not significantly different when compared to carbohydrate ( $8.7 \%$ vs. $5.4 \%$ respectively). The effects of maltodextrines ingestion however, has not been well documented. We have found no work focusing on thermic effect of maltodextrines at rest.

Compher et al. (2006) reviewed DIT studies and state that studies are commonly conducted for a 6-hour period. Shorter measures might not capture entire thermic effect. We assumed the 3-h measurement duration to be adequate enough, taking into account the energy content of test meal ingested. Values of elevated energy expenditure we measured did not returned to baseline, even after $180 \mathrm{~min}$. Figure 1 shows decreasing trends of both meals. Note that of the total DIT, approximately $90 \%$ (in HP meal) had been measured after 3 hours. Possibly, this could partly explain the lower overall thermic effect after HP meal. We tried to eliminate excessive fidgeting and restlessness of subjects (Poehlman et al., 1988).

The chosen energy density of the test meals corresponds with other studies (Denzer \& Young, 2003; Poehlman et al., 1988). Another determining factor explaining discrepant results might be palatability. Most of the subjects tolerated drinking the HP shake well, with contrast to the HC shake. Maltodextrin (nonsweetened carbohydrate) might fail to induce higher thermic effect (LeBlanc \& Labrie, 1997). This finding is supported by a study of Wallis et al. (2005) who used maltodextrin during exercise.

Possible errors of resting postprandial energy expenditure measurements in some cases may also be introduced by air leaks, incorrect calibration, fluctuating levels of fractional inspired $\mathrm{O}_{2}$ concentration, or acid-base disturbances. We tried however to eliminate all factors affecting resting energy expenditure measurements. We therefore calculate the inter- and intra-individual variability. The mean CVintra for measured RMR was $2.12 \pm 2.28 \%$. The mean CVinter was higher and reached $7.9 \%$. Both results stand within the generally accepted limits achieved recently by Bader et al. (2005).

To sum up, the research was limited by a number of subjects involved. Although we found the difference, the subject limitation brought discrepancy to the statistical analysis, which eventually displays insignificant differences, contradictory to the hypothesis. At this stage of the study, we are not able to answer to which extent body composition or fitness level could interfere the results or how to interpret results in detail. Oncoming research is needed to validate our results and clarify the answers. 


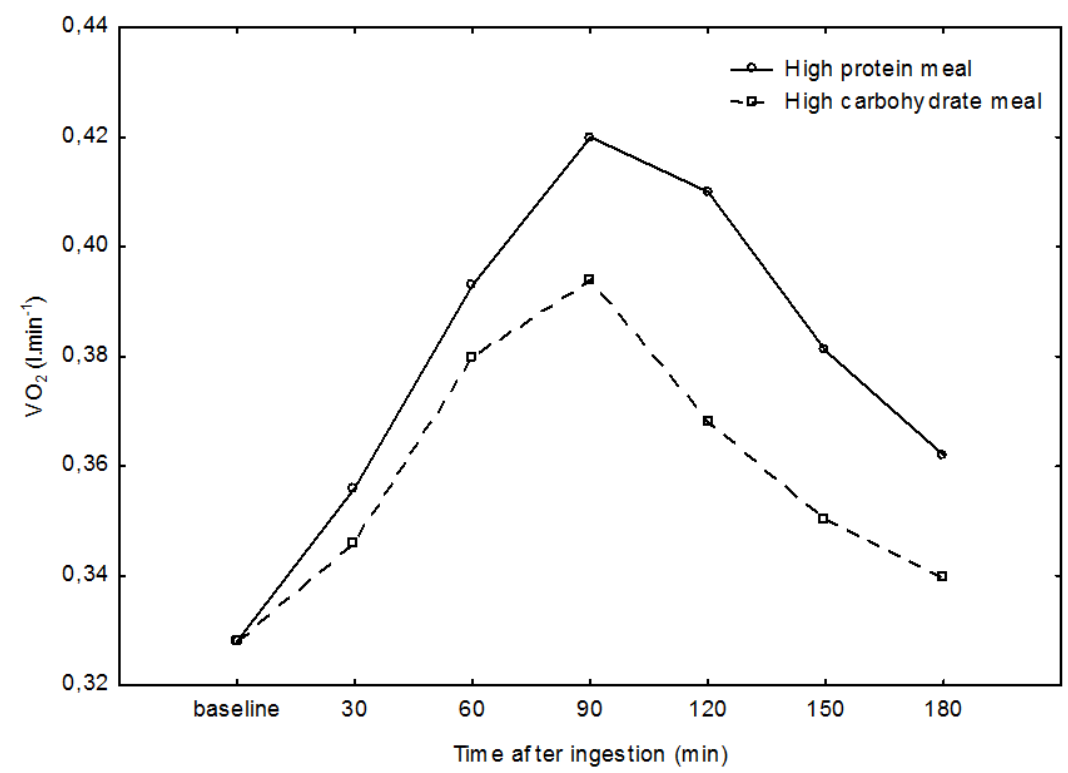

Figure 1. Metabolic response after test meal ingestion. Values are presented as a mean $\mathrm{VO}_{2}\left(l \cdot \mathrm{min}^{-1}\right)$ and were calculated based on assumption that baseline RMR remains constant throughout the test.

\section{CONCLUSIONS}

We conclude that the thermic response to maltodextrin and protein ingestion is comparable, with higher response after high protein meal. This small difference appears to have minimal practical application. The stage of the research possibly brought some inconsistence to the reproducibility of the results. However our findings predicted some indications and these should be tackled in the future research. We propose to supplement the study by the measuring the effect of mixture of proteins and maltodextrins.

\section{REFERENCES}

1. ACHESON KJ, BLONDEL-LUBRANO A, OGUEY-ARYAMON S, BEAUMONT M, EMADY-AZAR S, AMMON-ZUFFEREY C, MONNARD I, PINAUD S, NIELSEN-MOENNOZ C, BOVETO L. Protein choices targeting thermogenesis and metabolism. Am J Clin Nutr, 2011, 93: 525-534.

2. BADER N, WESPHAL-BOSY A, DILBA B, MULLER MJ. Intra- and interindividual variability of resting energy expenditure in healthy male subjects - biological and methodological variability of resting energy expenditure. British Journal of Nutrition; 2005, 94:843-849.

3. BLAAK EE, SARIS WH. Post-prandial thermogenesis and substrate utilization after ingestion of different dietary carbohydrates. Metabolism, 1996; 45:1235-42.

4. COMPHER CH, FRANKENFIELD D, KEIM N, ROTH-YOUSSEY L. Best practice methods to apply to measurement of resting metabolic rate in adults. J Diet Am Assoc, 2006; 106:881-903.

5. DENZER CHM, YOUNG JC. The effect of resistance exercise on the thermic effect of food. Int J Sport Nutr Exerc Metab, 2003; 13: 396-402.

6. LEBLANC J, LABRIE A. A possible role for palatability of the food in diet-induced thermogenesis. Int J Obes Relat Metab Disord , 1997; 21:1100-3. 
7. POEHLMAN ET, MELBY CL, BADYLAK SF. Resting metabolic rate and postprandial thermogenesis in highly trained and untrained males. Am J Clin Nutr, 1988; 47:793-798.

8. PRAT-LARQUEMIN L, KOPERT JM, BELLISLE F, GUY-GRAND B. Sweet taste of aspartame and sucrose: effects on diet-induced thermogenesis. Appetite, 2000; 34:245-251.

9. REEVES MM, DAVIES PSW, BAUER J, BATTISTUTTA D. Reducing the time period of steady state does not affect the accuracy of energy expenditure measurements by indirect calorimetry. (Abstract). J Appl Physiol, 2004; 97:130.

10. SCOTT CHB, DEVORE R. Diet-induced thermogenesis: variations among three isolcaloric mealreplacement shakes. Nutrition, 2005; 21:874-877.

11. STIPANUK HM. Biochemical, physiological molecular aspects of human nutrition. 2nd ed. St. Louis (US): Saunders Elsevier; 2006; 1212 p.

12. WALLIS GA, ROWLANDS DS, SHAW C, JENTJENS RL, JEUKENDRUP AE. Oxidation of combined ingestion of maltodextrins and fructose during exercise. Med Sci Sports Exerc, 2005; $37: 426-432$.

13. WEIR JB. New methods for calculating metabolic rate with special reference to protein metabolism. J Physiol, 1949; 109:1-9.

14. WESTERTERP KR. Diet induced thermogenesis. Nutr Metab, 2004; 1:5-10. 